\title{
Effect of Drought Stress on Crop Plants with Special Reference to Drought Avoidance and Tolerance Mechanisms: A Review
}

\author{
Diganta Deka ${ }^{1}$, Anil Kumar Singh ${ }^{2 *}$ and Alok Kumar Singh ${ }^{3}$
}

${ }^{1}$ Tocklai Tea Research Institute, Tea Research Association, Jorhat - 785008 (Assam), India

${ }^{2}$ Sri Murli Manohar Town Post Graduate College, Ballia - 277 001, (UP), India

${ }^{3}$ Narendra Deva University of Agriculture \& Technology, Kumarganj,

Faizabad - 224229 (U. P.), India

*Corresponding author

\begin{tabular}{|c|c|}
\hline & A B S T R A C T \\
\hline $\begin{array}{l}\text { Crop plants, Drought } \\
\text { stress, Drought } \\
\text { avoidance, Drought } \\
\text { tolerance }\end{array}$ & \multirow{3}{*}{$\begin{array}{l}\text { The changes in the climate due to global warming and ever dwindling arable land due to } \\
\text { the population pressure are increasing strain on available resources for sustainable food } \\
\text { production. Therefore, it is an urgent need to have proper idea about the effect of drought } \\
\text { stress on crop plants for getting stable production through research intervention. Water } \\
\text { deficit due to drought stress influences a wide range of plant processes, from whole plant } \\
\text { growth and development to the molecular regulation of essential transcriptional pathways, } \\
\text { and thus significantly impacts both physiology and metabolism. The studies about the } \\
\text { changes in behavior of crop plants under drought condition have progressed at a rapid pace } \\
\text { and extensive results of such analysis have been made public through various research } \\
\text { articles, which can now be easily accessed through the World Wide Web. This review } \\
\text { describes some aspects of drought induced effect of drought stress on different important } \\
\text { traits of crop plants. }\end{array}$} \\
\hline Article Info & \\
\hline $\begin{array}{l}\text { Accepted: } \\
\text { 18 August } 2018 \\
\text { Available Online: } \\
\text { 10 September } 2018\end{array}$ & \\
\hline
\end{tabular}

\section{Introduction}

The response of plants to drought stress is one of the most complex biological processes, and it involves numerous changes at the physiological, cellular, and molecular levels. Drought is the most frequent yield-reducing factor in arid and semiarid regions, although water deficit may occur even in high rainfall areas. The ultimate detrimental effect of drought stress is reduction in yield, as reported in major crops like rice (Venuprasad et al., 2007), wheat (Keshavarzi et al., 2013), and maize (Kamara et al., 2004) and some other important crops such as soybean (Kobraei et al., 2011) and chickpea (Khodadadi, 2013). Water stress due to drought can lead to major physiological and biochemical changes such as reduced photosynthesis (Zlatev et al., 2004; Tezara et al., 1999) and reprogramming of gene expression (Neill and Burnett, 1999; Pattanagul and Madore, 1999). Physiological changes under drought stress are often reflected at the transcription level, where the levels of mRNA related to key processes such as photosynthesis are down-regulated (Bartels and Salamani, 2001) and mRNA related to 
some antioxidative enzymes and some other useful molecules required for development of drought tolerant behaviour are upregulated.

\section{Effect of drought stress on physiological and morphological traits}

Drought stress, which results in water deficit is one of the most environmental stresses affecting agricultural production and productivity around the world and may result in considerable yield reduction. It affects both elongation and expansion growth (Anjum et al., 2003a; Kusaka et al., 2005; Shao et al., 2008). Water stress reduces the leaf area, cell size and intercellular volume (Kramer, 1969). A crop variety that is more resistant to water flow from the stomata into the atmosphere is considered as good for drought tolerance. The reduction in soil moisture may have led to lower water content in the leaves causing guard cells to loose turgor pressure and hence the size of stomatal pores are reduced (Tezara, et al., 2002) and/or causing stomatal closure. In addition, increased stomatal resistance may have led to reduced water transport in the leaves further causing a decrease in stomatal conductance. Reduction in stomatal conductance decreases transpiration with closing of the stomata, resulting prolong the plant survival by extending the period of availability of essential soil water reserves in the root zone. Stomatal closure also helps to maintain high leaf water content and thereby a higher leaf water potential, and leads to a reduction in photosynthetic activity (Hsiao, 1973). Higher photosynthetic rates could in turn favour a higher biomass and crop yields.

When plants experience water deficits, stomatal pores progressively close (Lawlor and Cornic, 2002). This process is regulated largely by leaf water potential but can be mediated by abscisic acid (ABA). Patil et al., (1984) reported that with the advance in stress, relative leaf water content decreased in different plant parts of five maize genotypes. In another study Schonfold et al., (1988) reported that relative leaf water content decreased proportionally with increasing stress. Ramakrishnayya and Murty (1991) studied the effect of soil moisture stress on physiological parameters of upland rice and revealed that with increase in soil moisture stress, relative leaf water content decreased. Water loss from plant tissue under drought condition results in growth inhibition and in a number of other metabolic and physiological changes (Mansfield and McAnish, 1995). Goyal et al., (2001) studied with two pearl millet hybrids raised in earthen pots under natural conditions of green house. In their experiment the stress levels i.e. mild stress (Soil moisture content, SMC, 7.0\%) and severe stress (SMC 4.5\%) were created by withholding irrigation at vegetative stages as compared to control (SMC 16.3\%). Revival (SMC $15.9 \%$ ) of severely stressed plants took 2 days after re-irrigation. A significant reduction in relative water content (RWC), water potential, osmotic potential and transpiration rate and increased in proline and leaf diffusive resistance were observed during stress condition which recovered partially following revival. In a field experiment conducted by Sharma et al., (2003) to study the effect of moisture stress on wheat genotypes grown under irrigated, mild stress and severe stress conditions the relative water content decreased significantly with increase in moisture stress. In a similar type of experiment on moth bean Garg et al., (2004) reported that water stress resulted in decrease of relative water content in six different genotypes. Yadav et al., (2005) also reported a decrease in the relative water content in sorghum plant under moisture stress conditions. A gradual decreased in relative water content was observed in tolerant genotypes of rice by Choudhary and his coworkers in the year 2005 . 


\section{Drought stress and photosynthesis}

Drought stress has greater impact on leaf photosynthesis and thus on yield of crop plants. In rice, as in other $\mathrm{C}_{3}$ cereals 60-90 percent of the carbon for grain development comes from photosynthetic activity of the flag leaf (Yoshida, 1981). Vu et al., (1987) conducted an experiment on soybean and observed that drought stress reduced the total extractable Rubisco activity and as a result limited the leaf photosynthesis under moisture stress condition. Li et al., (2000) reported that wheat grain weight is the function of rate and duration of grain growth and was affected by photosynthate supply. Drought stress reduced the photosynthate production because of the stomatal closure. The moisture stress treatment reduced the intercellular $\mathrm{CO}_{2}$ concentration, chlorophyll content and photosynthesis in Brassica cultivars (Das, 2003). Garg et al., (2004) reported that the rate of photosynthesis reduced in moth bean due to the moisture stress condition. The physiological response of short-term water deficits and its relief was assessed on water relations and accumulation of metabolites in sorghum hybrid $\mathrm{CSH}-14$ at vegetative, anthesis and grain filling stages. Stomatal conductance decreased drastically under stress and recovered partially after rewatering indicating its high sensitivity to water stress (Yadav et al., 2005). Stomatal closure leads to decreases in photosynthetic $\mathrm{CO}_{2}$ assimilation due to restricted diffusion of $\mathrm{CO}_{2}$ into the leaf and altered $\mathrm{CO}_{2}$ metabolism. Decreased $\mathrm{CO}_{2}$ diffusion from the atmosphere to the site of carboxylation is generally considered the main cause for decreased photosynthesis under mild to moderate water limitation (Chaves et al., 2003, 2009; Flexas et al., 2004; Grassi and Magnani, 2005). Pelleschi et al., (1997) also observed that reduced $\mathrm{CO}_{2}$ diffusion during stomatal closure is mainly responsible for the decline in photosynthesis in $\mathrm{C}_{3}$ plants subjected to dehydration.
However, Tezara et al., (1999) reported that, the photosynthetic rate is limited more by altered $\mathrm{CO}_{2}$ metabolism than by reduced diffusion in sunflower (Heliathus annuus) under water stress. The lower $\mathrm{CO}_{2}$ availability inhibits carbon assimilation, and ultimately photosynthetic capacity is lost as a consequence of the reduced stomatal conductance and/or direct damage to carbon metabolism (Bartels and Salamini, 2001; Colom and Vazzana, 2003). According to Flexas and Medrano (2002), there is a long standing controversy as to whether drought limits photosynthetic $\mathrm{CO}_{2}$ assimillation through stomatal closure or by metabolic impairment in $\mathrm{C}_{3}$ plants. Comparison of results from different studies is difficult due to interspecific differences in response of photosynthesis to leaf water potential and/or relative water content (RWC), the most commonly used parameters to assess the severity of drought. Therefore, stomatal conductance (g) used as a basis for comparison of metabolic processes in different studies. The logic is that, as there is a strong link between stomatal conductance and photosynthesis (perhaps co-regulation between them), so different relationships between RWC or water potential and photosynthetic rate and changes in metabolism in different species and studies may be normalized by relating them to conductance.

\section{Root and leaf characteristics in relation to drought stress}

The presence of cuticular wax is also important for water stress and is more in dry land adopted crop plants as compare to the irrigated. The presence of cuticular wax resulted in thicker and leathery leaves which prevent the water loss from the surface. The leaf rolling character and death of leaves are good criteria found useful in assessing levels of drought tolerance in large scale screening 
of different crop plants, viz. rice (Chang, et al., 1974). Leaf of any crop plant frequently rolls when plants is suffering from water stress condition. When leaf temperature is increases, the stomata become close and transpiration rate decreased sharply with leaf rolling (Sobarado, 1987). Leaf attributes can be incorporated for improvement of drought tolerance in crops. Type of root system is also a good selection criterion for selecting the drought tolerance line or varieties. Deep root system has been identified as the targeted for drought tolerance improvement (Boyer, 1996). Production of root system under drought is very important and had good correlation with yield under moisture stress (Darofeev and Tyselano, 1982). Studies on root related characteristics have elicited much interest because it is through roots that crop plant up take moisture and show a wide range of varietal differences. Furthermore, drought stress caused pronounced changes in root structure such as increased branching and density (Eghball and Maranville, 1993). Cultivars having deep and thick roots are good for drought stress condition and are positively correlated with xylem vessel area, which are vital to the conductance of water from soil to the upper parts of the plants to meet the evaporative demand. Large and vigorous root system and the continued production of new root hairs are required for maximum response to nutrients supply and optimum environmental conditions and that this positively correlates with the dry matter accumulation within the shoot (Willumsen, 1993). Drought affected plants generally exhibit small root system configuration and in many cases the reduction in size of root system is directly proportional to the magnitude of water storage. According to Slayter, 1973 two types of effects of water deficit on root development can be exposed, first is reduction in rate of meristmetic activity and root elongation directly associated with the level of internal water deficit and second effect of suberization on the water and nutrients uptake proportional of the root system as whole. High dry weight under water stress conditions is a desirable characteristic for survivability of the plant under water stress condition. A common adverse effect of water stress on crop plant is reduction in fresh and dry biomass production (Farooq et al., 2009). Morphological characters viz., early maturity, early vigor, rapid growth and physiological characters viz., diffusive resistance of stomata, osmotic adjustment, leaf rolling, closing and opening of stomata, position of stomata, leaf water retention and leaf senescence were associated with drought tolerance (Singh, 1993).

\section{Drought avoidance and tolerance mechanisms in plants}

Generally plants use two types of mechanisms to cope up with drought stress, viz. drought avoidance and drought tolerance mechanisms. A combination of these two defines drought resistance in its physiological context according to Levitt (1972).

The plants having the capacity to avoid drought can complete their life cycle without developing severe water deficits. Some ephemerals have a very short life cycle which can be completed during a brief rainy season while some other plants exhibit adaptations to increase water uptake and reduce water loss and thus avoid the debilitating consequences of drought that other plants might feel (Bartels and Salamini, 2001; Laporte et al., 2002; Verslues et al., 2006). In a general sense drought avoidance consists of mechanisms that reduce water loss from plants due to stomatal control of transpiration, and also maintain water uptake through an extensive and prolific root system (Turner et al., 2001; Kavar et al., 2007). Thus developing a more extensive root system by certain plants is a drought-avoiding strategy. 
It is an almost universal observation that the root: shoot ratio increases with water stress. Increase in root weight may be due to a greater density of roots (Turner, 1979). Under water stress condition/water scarcity the upper soil layers usually dry first and the new root growth extends into the moist soil zones. Accordingly, shallower roots are common in wetter soils as contrast to deeper roots systems in dryer soils (Taiz and Zeiger, 1998). Having a deep and thick root system, which allows access to water deeper in the soil is considered important in determining drought resistance in rice (Price et al., 2002), Arabidopsis thaliana (Xiong et al., 2006), pea (Chiantante et al., 1999), Festuca arundinacea (Ervin and Koski, 1998), and Wilwitchia mirabilis (Fitter and Hay, 2002). Hence, greater root growth and improved morphological development can result in drought avoidance. Some development in shoots also plays important role in water stress responses. At the onset of the dry season, a desert plant Zygophyllum qatarense responds to water stress with a leaf polymorphism in which it replaces the wetseason foliage with unifoliate, xeromorphic leaves. As the dry season progresses, the plant reduces its leaf area substantially (Sayed, 1996).

Some plants use various strategies to tolerate the drought situation. Glaucousness or waxy bloom on leaves helps in maintenance of high tissue water potential, and is therefore considered as a desirable trait for drought tolerance (Richards et al., 1986; Ludlow and Muchow, 1990). Under water stress condition the leaves of many plants frequently wilt and droop (or roll, in the case of many grasses), and this type of response reduces the interception of radiation, thereby counteracting the increase in leaf temperature arising from stomatal closure and preventing further development of leaf water deficit (Turner, 1979). Reduced leaf area can also be a mechanism for moderating water use and injury under drought stress condition (Blum, 2005). Severe drought stress may result in the production of increased levels of $\mathrm{ABA}$ and subsequent leaf abscission, thereby reducing transpirational demand. Such developmental changes within a plant during water stress are important morphological drought-avoiding adaptations that help in maintaining the plant's water potential at some functional level in the midst of potential water limitation.

When drought stress becomes more severe, gradually it becomes more difficult to avoid dehydration; and mechanisms that allow plants to withstand reduced water content (more negative water potentials) become increasingly important. Drought tolerance is defined as the ability of plants to continue to function at lowered tissue water potentials. Drought-tolerating mechanisms often involve the maintenance of turgor (by accumulation of solutes) and/or desiccation tolerance (by protoplasmic resistance) (Jones et al., 1981). "Desiccation tolerant" plants can recover from a fully air-dried state (Vicre et al., 2004). When dehydrated, these plants are in a metabolically dormant, or cryptobiotic, state. Mesophytic plants, including all crop plants, lack the ability to enter the cryptobiotic state. In reality, mesophytes typically cannot recover from severe (approximately $50 \%$ or greater) decreases in water content (Verslues et al., 2006). Still, many plants have some ability to tolerate significant water loss, while maintaining metabolic activity.

Some biochemical and physiological studies have shown that sugars (e.g., raffinose family oligosaccharides (RFO), sucrose, sorbitol, and mannitol), amino acids (e.g., proline), and amines (e.g., glycine betaine) accumulate under drought stress in different plant species (reviewed by Seki et al., 2007). As soil dries, its water potential becomes more negative. 
Accumulation of solutes (osmolytes) by plant tissues makes their water potentials more negative, allowing them to take up water from site having positive water potential as compared to their tissues and thus avoid reductions in turgor. This drought-tolerating mechanism is called osmotic adjustment (OA). By contributing towards OA, osmolytes act as protectants for plants subjected to low water potential (Pandey et al., 2004). OA helps maintain cell turgor, which can allow cell enlargement and plant growth during water stress; and it can allow stomata to remain at least partially open and $\mathrm{CO}_{2}$ assimilation to continue at water potentials that would be otherwise inhibitory (Alves and Setter, 2004). OA by osmolytes has been reported to be a cause of improved productivity in wheat (Flower and Ludlow, 1987), sorghum (Sorghum bicolor), barley (Hordeum vulgare), chickpea (Cicer arietnum), pigeon pea (Cajanus cajan) (Khanna-Chopra and Khanna-Chopra, 2004), and rice (Lanceras et al., 2004). In addition to acting as osmolytes to maintain turgor for a longer period of time, during drought condition some of the accumulated solutes are thought to participate in stress-protective functions as free radical scavengers and for stabilization of macromolecules (Abebe et al., 2003; Seki et al., 2007). In a research work conducted by Ram and Singh in 1988 water stress imposed at the tillering and boot stages of growth in rice genotypes led to accumulation of free proline in appreciable quantity; the accumulation being more in stress tolerant rice genotypes than in susceptible one. When the imposed stress was released, they noticed that it resulted in rapid disappearance of the accumulated proline. Stress induced proline accumulation in rice with different varietal responses had also been reported by Dingkuhn et al., (1991). In their study 45 day old seedlings of drought resistant (N-22, CR 143-2-2) and susceptible rice (Oryza sativa L.) genotypes (Panidhan,
Pusa-169) were subjected to osmotic stress in PEG-6000 solution of (-10) and (-16) bars and the relative water content, proline content and pyrroline-5-carboxylate synthetase (P5CS) activity and its P5CS expression were studied. Proline content increased both in susceptible and tolerant genotypes but the increase was higher in tolerant genotypes (Choudhary, 2005). Kale (2006) studied the proline contents during stress and non-stress conditions in 18 species belonging to 15 genera of Pteridophytes from Western Ghats of South India. He observed that the accumulation of free proline is generally associated with the drought resistant capacity of the plant. Proline influences stress probably through its effect on the degradation of chlorophylls and accumulation of carotenoids in ferns. In most of the species studied presently, proline contents increase during fertile state of the plant.

\section{Biochemical/Metabolic/Genomic responses associated with drought resistance}

In various plants that adapt to water stress condition, a set of genes are transcriptionally activated, leading to accumulation of new proteins in seeds and vegetative organs and greater tolerance to drought. The LEA (Late Embryogenesis Abundant) proteins, which were first characterized in cotton (Gossypium hirsutum), are a set of proteins that accumulate in embryos late in seed development (Xu et al., 1996) where they are associated with acquisition of desiccation tolerance in maturing seeds. These proteins are also found in vegetative tissues in response to exogenous $\mathrm{ABA}$, as well as in osmotic and dehydration stress condition (Liang et al., 2005), at any stage of plant development (Baker et al., 1988). At least six groups of LEA proteins have been categorized by virtue of the similarity in their deduced amino acid sequences; and group 2, also referred to as the dehydrins, contain 
proteins that are induced by dehydrationrelated stresses such as osmotic stress and drought (Wang et al., 2006). Their hydrophilic nature and high solubility indicate that the proteins are maintained in the cytosol, where they are supposed to function as chaperone-like protective molecules to combat cellular damage (Umezewa et al., 2006) and to act as hydrophilins, retaining water (Reyes et al., 2008) during dehydration. An association between tolerance to drought stress and these groups of proteins has been observed in some crop plants. In blueberry (Vacinium spp.), the dehydrins were found to accumulate in response to changes in ABA levels during drought stress (Panta et al., 2001). LEA genes, when over-expressed in rice (Xiao et al., 2007), tobacco (Nicotiana tabacum) (Wang et al., 2006), and Arabidopsis thaliana (Figueras et al., 2004) lead to drought tolerance in transgenic plants. Although the specific roles of the LEA proteins are not known, it is clear that they are regulated by $\mathrm{ABA}$ and cellular water loss.

In a true sense majority of the plant cells, including photosynthetic cells, are protected against the detrimental effects of reactive oxygen species (ROS) by an antioxidant system that has been associated with stress tolerance in plants. This system is composed of enzymatic and non-enzymatic detoxification mechanisms, which mitigate and repair damage initiated by the ROS (Fu and Huang, 2001; Zhang and Kirkham, 1996). The enzymatic system is made of the enzymes superoxide dismutase (SOD), catalase (CAT), peroxidase (POD), ascorbate peroxidase (APX), and glutathione reductase (GR) (Li et al., 1998; Mittler, 2002). First and foremost, SOD reacts with the superoxide radicals to generate $\mathrm{H}_{2} \mathrm{O}_{2}, \mathrm{H}_{2} \mathrm{O}$, and molecular oxygen $\left(\mathrm{O}_{2}\right)$. The $\mathrm{H}_{2} \mathrm{O}_{2}$ so produced is disposed off by APX, POD, and CAT. APX and GR take part in the ascorbate-glutathione cycle, where $\mathrm{H}_{2} \mathrm{O}_{2}$ is removed and ascorbic acid is regenerated (Li et al., 1998; Smirnoff, 1993; Thomson, 1987; Zhang and Kirkham, 1996). Additionally, GR maintains a high ratio of reduced glutathione (GSH) to oxidized glutathione (GSSG), which can further protect chloroplasts against oxidative damage (Gamble and Burke, 1984). Some other enzymes related to glutathione metabolism, glutathione S-transferase (GST) (acting as peroxidase) and glutathione peroxidase (GPX), have been reported to be induced under drought stress in moss (Tortula ruralis) and leafy spurge (Euphorbia esula) and are efficient scavengers of $\mathrm{H}_{2} \mathrm{O}_{2}$ and lipid peroxide using reduced glutathione and preferably thioredoxin as a reductant (Cruz de Carvalho, 2008).

In recent times, increasing evidence for the participation of thioredoxins (TRX) and glutaredoxins (GRX) in plant antioxidant defense system has emerged (Meyer et al., 2009). Thioredoxins (TRX) and glutaredoxins (GRX) constitute families of thiol oxidoreductases (Meyer et al., 2012). In higher plants, these proteins are distributed in the cytoplasm, plasma membrane, endoplasmic reticulum, nucleus, apoplast, mitochondrion, and chloroplast (Iqbal et al., 2006). Drought-induced ROS can oxidize SH-containing enzymes of the chloroplast. TRX act to reduce the oxidized -S-S- groups in these enzymes, reforming them into the active - SH groups (Buchanan and Balmer, 2005). These proteins are induced under drought stress and play a role in drought resistance by supplying reducing power to enzymes, repairing oxidized proteins, or regulating scavenging mechanisms (Dos Santos and Rey, 2006). For example, in some cases, glutathione peroxidase (GPX) appears to prefer TRX to glutathione as a reductant during scavenging of $\mathrm{H}_{2} \mathrm{O}_{2}$ and lipid peroxides (Cruz de Carvalho, 2008). A potato (Solanum tuberosum) mutant in TRX CDSP32 exhibited high sensitivity to 
oxidative stress generated by methyl viologen compared to the wild type and transgenic plants over expressing gene (Rey et al., 2005). Methyl viologen generates ROS from photosystem I, which oxidize the -SHcontaining enzymes (Kotabova et al., 2008). TRX is required to reverse this damage. Differential expression of a TRX between drought-tolerant and susceptible genotypes of wheat was identified by proteomic studies (Hajheidari et al., 2007). Higher level expression of the protein was there in drought-tolerant genotype than in susceptible genotypes. Therefore, TRX can be seen to play a role in drought tolerance by taking part in antioxidant defence systems in plants.

Increased activities of SOD, CAT, APX, and GR, was exhibited by wheat leaves exposed to mild water stress $(-0.5 \mathrm{MPa})$, which was correlated with reduced lipid peroxidation; but the protective system was not effective at a more severe water stress (-1.5 MPa) (Baisak et al., 1994). These results suggest that the degree of water stress is also important in the system's protection and that it may represent a drought-tolerance response. However, drought tolerance was associated with scavenging systems represented by APX and CAT in wheat (Sairam et al., 1998) and cowpea (Vigna anguiculata) (D'ArcyLamenta et al., 2006). Transgenic plants overexpressing SOD and APX were resistant to oxidative-stress-inducing chemicals methyl viologen (Tang et al., 2006) and paraquat (Lee et al., 2007) in potato and tobacco, respectively; and overexpression of APX in tobacco (Badawi et al., 2004) and GPX in Arabidposis (Miao et al., 2006) enhanced tolerance to water deficit. In case of Phaseolus species, the drought-tolerant $P$. acutifolius has higher constitutive expression of SOD, CAT, and APX than the sensitive $P$. vulgaris (Turkan et al., 2005). Studies with $P$. vulgaris cultivars differing in drought tolerance showed that tolerant cultivars maintain stable GR expression during drought stress compared to susceptible cultivars (Torres-Franklin et al., 2008). Though effectiveness against stress may be determined by the level of stress, these comparative and transgenic approaches showed that the enzymatic antioxidant system can be an indicator of drought tolerance in different plants.

Antioxidants such as lipophilic vitamin E ( $\alpha$ tocopherol), hydrophilic vitamin $\mathrm{C}$ (ascorbic acid), and carotenoids are involved in nonenzymatic detoxification mechanisms. Vitamin E reacts with $\mathrm{O}_{2}^{-}$as well as ${ }^{1} \mathrm{O}_{2}$. Vitamin $\mathrm{C}$ can react directly with $\mathrm{H}_{2} \mathrm{O}_{2}$ in a reaction mediated by APX (Smirnoff, 1993). Glutathione is the substrate for the formation of vitamin $\mathrm{C}$, which has the ability to react directly with free radicals such as $\mathrm{OH}$ (Pastori and Trippi, 1992). Vitamin E, Vitamin C, and glutathione have been reported to increase in plants under water stress (Shao et al., 2008). Transgenic plants with greater levels of transcripts encoding enzymes associated with the glutathioneascorbate cycle accounted for lower levels of $\mathrm{H}_{2} \mathrm{O}_{2}$ during drought (Rivero et al., 2007). The transgenic plants had higher photosynthesis and water use efficiency and higher survival rate under severe drought. In addition to their role in energy dissipation in plant tissues, the carotenoids, particularly $\beta$ carotene, remove singlet oxygen $\left({ }^{1} \mathrm{O}_{2}\right)$. Stuhlfauth et al., (1990) reported an increase of total carotenoid after one day of stress in leaf disks of two oak (Quercus) species. At low water potential $(-2.5 \mathrm{MPa})$, there was a 25 per cent increase in $\beta$-carotene and a concurrent decrease in ${ }^{1} \mathrm{O}_{2}$ levels, suggesting protection against this ROS (Stuhlfauth et al., 1990). Drought tolerance in the shrub species Cistus clusii was found to be associated with higher levels of $\alpha$-tocopherol and $\beta$-carotene than in Cistus albidus (Munne-Bosch et al., 2003). Furthermore, the tolerant species had 
negligible chlorophyll degradation and deepoxidation of violaxanthin in the xanthophyll cycle, and this was explained by better protection against oxidative stress by $\alpha$ tocopherol and $\beta$-carotene during drought stress. In summary, the ROS generated under water deficit condition can be counteracted in drought-tolerating plants by the activation of antioxidant systems to remove the ROS from the affected cells. Relative studies have identified association between drought tolerance and activities of the antioxidant systems in different plants. However, effectiveness of the system might depend on the degree of water deficit, as high levels of stress could also cause damage to the antioxidant system itself.

A different group of proteins that are induced by abiotic stress is the heat shock proteins (HSP). Five major families of HSP are recognized: the HSP70 (DnaK) family, the chaperonins (HSP60), the HSP90 family, the HSP100, and the small heat shock protein (sHSP) family (Wang et al., 2004). Among these families, generally the sHSP have been associated with abiotic stress. Initially detected upon heat treatment, sHSP production has now been observed under drought stress. Although mechanisms by which sHSP are involved in cell protection are not fully understood, there is strong evidence supporting the view that they function as molecular chaperones that bind to misfolded substrate proteins and thereby prevent irreversible aggregation during stress (Sun et al., 2002). Synergistic cooperation between sHSP, p26, and the sugar trehalose in the protection of citrate synthase during thermal stress has been observed in vitro (Viner et al., 2001). Hamilton and Heckathorn (2001) demonstrated that electron transport of mitochondrial complex I was protected by sHSP upon salt stress, with similar effects to that of ascorbate, glutathione, and $\alpha$ tocopherol as well as SOD and CAT. The results provide evidence that sHSP may protect plants from stress by cooperation with other stress-protective molecules such as sugars, amino acids, or amines and/or by mechanisms involving ROS scavenging.

Generally heat shock proteins (HSPs) are involved in drought and heat tolerance. It's involvement in drought has been studied through comparative and transgenic approaches. Qualitative differences in the pattern of synthesis of HSP were observed in maize lines differing in drought and heat tolerance (Ristic et al., 1991). A unique HSP was observed in a drought and heat-resistant line compared to a sensitive line. Differential HSP expression was also observed in potato genotypes differing in drought tolerance (Vasquez-Robinet et al., 2008). Although HSP70, HSP40, and a sHSP, whose products localize to the chloroplast were induced in a drought-tolerant genotype, HSP genes targeted to the cytosol were induced in the sensitive genotype. This differential expression in different genotypes and organelles implies roles for HSP in drought tolerance. A higher level expression of sHSP enhanced drought tolerance in rice (Sato and Yokoya, 2008) and Arabidopsis (Sun et al., 2001).

\section{Some important drought resistance genes and pathways}

A lot of genes that are known to respond to drought stress have been identified, and the products of these genes can be classified into two groups (Bray, 1997; YamaguchiShinozaki and Shinozaki, 2006). The first group includes proteins that perhaps directly protect against stress such as enzymes for osmolyte biosynthesis, LEA proteins, and detoxification enzymes. The second group consists of proteins involved in the regulation of gene expression and signal transduction of stress responses, such as transcription factors 
(TF), protein kinases, protein phosphatases, and enzymes involved in biosynthesis of signaling molecules.

In case of water deficit stress, the phytohormone ABA accumulates in larger amount. Increased ABA concentration leads to many changes in plant development, physiology, and growth. Some of these changes bring about avoidance and tolerance mechanisms in plants under water stress conditions. At the molecular level, ABA induces expression of several genes mediated through ABA-responsive cis and trans-acting factors and protein kinases or phosphatases in a $\mathrm{Ca}^{2+}$ dependent or independent signaling cascade (Bray, 2002; Nakashima et al., 2009). ABA-dependent pathways regulate stressresponsive gene expression through $\mathrm{CBF} 4$, MYB/MYC, and bZIP-type TF, which bind CRT/DRE, MYBR/MYCR-recognition sequences, and ABA-responsive elements (ABRE), respectively. These pathways are induced by drought as well as salinity stress.

Several genes are recognized to be induced by drought, salinity, and cold in aba (ABAdeficient) and abi (ABA-insensitive) Arabidopsis mutants. This suggests the existence of alternative, ABA-independent regulatory systems of gene expression during stress responses. In fact there is an ABAindependent pathway whose genes have one or several copies of the CRT/DRE cis elements in their promoters. A family of TF known as CBF or DREB1 binds to this element and activates transcription of the downstream dehydration-responsive genes (Stockinger et al., 1997). DREB1 TFs are believed to interact with CRT/DRE and induce expression of stress-tolerance genes in response to cold, whereas DREB2 TFs are involved in drought responses (Liu et al., 1998; Seki et al., 2001). A higher level of expression of the Arabidopsis DREB1A TF under the control of a stress-inducible promoter (RD29A) increased drought tolerance in wheat (Pellegrineschi et al., 2004). In a study with DREB1 expressing tobacco, transgenic plants had improved drought and low-temperature stress tolerance (Kasuga et al., 2004). All these information indicate that, even in ABA-independent pathways, plants have common mechanisms in their physiological responses and tolerance to drought.

Although it is important to identify genes that protect and maintain cellular structure and function under drought stress, the major focus should be to improve crop yield by increasing carbon gain in such condition. Therefore, it is desirable to target genes which are responsible for increasing water use efficiency (WUE) without incurring yield penalties. This may be difficult, because improving WUE is often accompanied by decreased photosynthesis (Flexas et al., 2004) and yield (Condon et al., 2004). Though, genes that can modify transpiration efficiency by acting on epidermal and mesophyll development or stomatal density and porosity may circumvent this problem. A gene that directly regulates plant transpiration has been identified in Arabidopsis (Masle et al., 2005). This is the regulatory gene ERECTA, encoding a leucine-rich repeat receptor-like kinase. Its expression led to high photosynthesis and low stomatal conductance, which resulted in high WUE (Masle et al., 2005). Some other regulatory genes that have been found to control stomatal conductance are OST, encoding a protein kinase (Mustilli et al., 2002) and ABF3 and ABF4 TF (Kang et al., 2002). A higher level of expression of OST1, ABF3, and ABF4 in transgenic plants resulted in reduced transpiration (Kang et al., 2002; Mustilli et al., 2002).

In a study conducted by Aharoni et al., in 2004, an ERF/AP2 TF gene SHINE (SHN) displayed drought resistance in Arabidopsis. 
The expression of this gene in rice and tomato confers drought resistance, increases WUE and biomass production, and reduces wholeplant transpiration (Karaba, 2007). A dominant gain-of-function Arabidopsis mutant of HARDY (HRD) gene belonging to the ERF/AP2 family of TF termed hrd-D was identified (Karaba et al., 2007). Expression of the Arabidopsis HRD gene in rice improved water use efficiency by enhancing photosynthesis and reducing transpiration. In addition, plants exhibited drought tolerance, lowered water consumption, increased shoot biomass under well-watered conditions, and an adaptive increase in root biomass under drought stress. While a higher level of expression of HRD in Arabidopsis produces smaller plants with thicker leaves and more chloroplast-bearing mesophyll, in rice there is an increase in leaf biomass and bundle sheath cells that probably contribute to enhanced photosynthetic assimilation and efficiency.

Drought stress is a universal problem, constraining the growth and development of crop plants and thus affects the global crop production and quality of produced items. The recent global climate change has made this situation more serious. Following drought, stomata close progressively with a parallel decline in net photosynthesis and water-use efficiency. Depending upon the availability of moisture, activities of the enzymes of carbon assimilation and those involved in adenosine triphosphate synthesis are decreased and sometimes inhibited. One of the major factors responsible for impaired plant growth and productivity under drought stress is the production of reactive oxygen species in organelles including chloroplasts, mitochondria and peroxisomes. The drought tolerance mechanism involves a number of physiological and biochemical processes at cell, tissue, organ and whole-plant levels, when activated at different stages of plant development. Examples of these mechanisms are reduction in water loss by increasing stomatal resistance, increased water uptake by developing large and deep root systems, accumulation of osmolytes and osmoprotectant synthesis. Scavenging of reactive oxygen species by enzymatic and non-enzymatic systems, cell membrane stability, expression of aquaporins and stress proteins are also vital mechanisms of drought tolerance. Although physiological mechanisms of drought tolerance are relatively well understood, further studies are essential to determine the physiological basis of assimilate partitioning from source to sink. The plant phenotypic flexibility which leads to drought tolerance and factors that modulate plant drought-stress responses are also some areas where in depth study is still needed. The applications of genomics, proteomics and trascriptomic approaches for better understanding of the molecular basis of plant drought tolerance and improved water-use efficiency under drought are also urgent. The molecular knowledge of drought stress response and the drought tolerance mechanisms is likely to pave the way for engineering plants that can withstand and give satisfactory economic yield under drought stress.

\section{References}

Aharoni, A., Dixit, S., Jetter, R., Thoenes, E., van Arkel, G. and Pereira, A. (2004). The shine clade of AP2 domain transcription factors activates wax biosynthesis, alters cuticle properties, and confers drought tolerance when overexpressed in Arabidopsis. Plant Cell 16: 2463-2480.

Alves, A.A.G. and Setter, T.L. (2004). Abscisic acid accumulation and osmotic adjustment in cassava under water deficit. Environ. Exp. Bot. 51: 259-279.

Anjum, F., Yaseen, M., Rasul, E. Wahid, A and Anjum, S. 2003a. Water stress in 
barley (Hordeum vulgare L.). I. Effect on morphological characters. Pak. J. Agric. Sci., 40: 43-44.

Badawi, G.H., Kawano, N., Yamaguchi, Y., Shimada, E., Sasaki, R., Kubo, A. and Tanaka, K. (2004). Enhanced tolerance to salt stress and water deficit by overexpressing superoxide dismutase in tobacco (Nicotiana tabacum) chloroplasts. Physiol. Plant. 121: 231238.

Baisak, R., Rana, D., Acharya, P.B.B. and Kar, M. (1994). Alterations in the activities of active oxygen scavenging enzymes of wheat leaves subjected to water stress. Plant Cell Physiol. 35: 489-495.

Baker, J.C., Steele, C. and Dure, L. (1988). Sequence and characterization of 6 LEA proteins and their genes from cotton. Plant Mol. Biol. 11: 277-291.

Bartels, D. and Salamini, F. (2001). Desiccation tolerance in the resurrection plant Craterostigma plantagineum. A contribution to the study of drought tolerance at the molecular level. Plant Physiol. 127: 1346-1353.

Blum, A. (2002). The Mitigation of Drought Stress. Plant stress.com

Boyer, J.S. 1996. Advances in drought tolerence in plants. Adv. Agron., 56: $187-218$.

Bray, E.A. (1997). Plant responses to water deficit. Trends Plant Sci. 2: 48-54.

Bray, E.A. (2002). Classification of genes differentially expressed during waterdeficit stress in Arabidopsis thaliana: an analysis using microarray and differential expression data. Ann. Bot. 89: 803-811.

Buchanan, B.B. and Balmer, Y. (2005). Redox regulation: a broadening horizon. Ann. Rev. Plant Biol. 56: 187-220.

Chang, T.T., Loresto, G.C. and Tagumpay, O. 1974. Screening of rice germplasm for drought resistant. Sabrao J., 6(1): 9-16.
Chaves, M.M., Flexas, J. and Pinheiro, C. (2009). Photosynthesis under drought and salt stress: regulation mechanisms from whole plant to cell. Ann. Bot. 103: 551-560.

Chaves, M.M., Pereira, J.S. and Maroco, J. (2003). Understanding plant response to drought from genes to the whole plant. Funct. Plant Biol. 30: 239-264.

Choudhary, N.L., Sairam R.K. and Tyagi, A. (2005). Expression of $\Delta^{1}$-pyrroline-5carboxylate synthetase gene during drought in rice (Oryza sativa L.). Indian J. Biochem. Biophys. 42: 366-370.

Colom, M.R. and Vazzana, C. (2003). Photosynthesis and PS II functionality of drought resistant and droughtsensitive weeping love grass plants. Environ. Exp. Bot. 49: 135-144.

Condon, A.G., Richards, R.A., Rebetske, G.J. and Farquhar, G.D. (2004). Breeding for high water use efficiency. J. Exp. Bot. 55: 2447-2460.

Cruz de Carvalho, M.H.C. (2008). Drought stress and reactive oxygen species: production, scavenging and signaling. Plant Sign. Behav. 3: 156-165.

D'Arcy-Lamenta, T., Ferrari-Iliou, R., Contour-Ansel, D., Pham-Thi, A.T. and Zuily-Fodil, Y. (2006). Isolation and characterization of four ascorbate peroxidase cDNAs responsive to water deficit in cowpea leaves. Ann. Bot. 97: 133-140.

Darofeev, V.F. and Tyselano, A.M. 1982. Number of seminal roots in spring wheat in the course of selecting pair for hybridization. Vestnik Selokokhozysist., 8:50-56.

Das, R. (2003). Characterization responses of Brassica species to elevated $\mathrm{CO}_{2}$ under moisture stress condition. Ph.D. Thesis, Indian Agricultural Research Station, New Delhi-12.

Dat, J., Vandenabeele, S., Vranova, E., Van Montangu, M. and Van Breusegem, F. 
(2000) Dual action of the active oxygen species during plant stress responses. Cell Molec. Life Sci. 57: 779-795.

Dingkuhn, M., Cruz, R.T., O’Toole, J.C., Turner, N.C. and Doerffling, K. (1991). Responses of seven diverse cultivars to water deficit III. Accumulation of proline in relation to leaf water potential and osmotic adjustment. Field Crop Res. 27: 103-117.

Dos Santos, C.V. and Rey, P. (2006). Plant thioredoxins are key actors in the oxidative stress response. Trends Plant Sci. 11: 1329-1334.

Eghball, B. and Maranville, J.W. 1993. Root development and nitrogen influx of corn genotypes grown under combined drought and nitrogen stress. Agron. J., 85: 147-152.

Ervin, E.H. and Koski, A.J. (1998). Drought avoidance aspects and crop coefficients of Kentucky bluegrass and tall fescue turfs in the semiarid west. Crop Sci. 38: 788-795.

Farooq, M., Wahid, A., Kobayashi, N., Fujita D. and Basra, S.M.A. 2009. Plant drought stress: effects, mechanisms and management. Agron. Sustain. Dev., 29: 185-212.

Figueras, M.J., Pujal, A., Saleh, R., Save, M., Pages, M. and Goday, A. (2004). Maize RAB17 overexpression in arabidopsis plants promotes osmotic stress tolerance. Ann. Appl. Biol. 144: 251257.

Fitter, A.H. and Hay, R.K.M. (2002). Environmental physiology of plants. Academic Press. San Diago.

Flexas, J. and Medrano, H. (2002). Droughtinhibition of photosynthesis in $\mathrm{C} 3$ plants: stomatal and non-stomatal limitations revisited.

Flexas, J., Bota, J., Cifre, J., Escalona, J.M., Galmes, J., Gulias, J., Lefi, E.K., Martinez-Carnellas, S.F., Moreno, M.T., Ribas-Carbo, M., Reira, D.,
Sampol, B., Medrano, H. (2004). Understanding down-regulation of photosynthesis under water stress: Future prospects and searching for physiological tools for irrigation management. Ann. Appl. Biol. 144: 273283.

Flexas, J., Bota, J., Loreto, F; Cornic, G. and Sharkey, T.D. (2004). Diffusive and metabolic limitations to photosynthesis under drought and salinity in $\mathrm{C} 3$ plants. Plant Biol. 6: 269-279.

$\mathrm{Fu}, \mathrm{J}$. and Huang, B. (2001). Involvement of antioxidants and lipid peroxidation in the adaptation of two cool-season grasses to localized drought stress. Environ. Exp. Bot. 45: 105-114.

Gamble, P.E. and Burke, J.J. (1984). Effect of water stress on the chloroplast antioxidant system I. Alterations in glutathione reductase activity. Plant Physiol. 76: 615-621.

Garg, B.K., Burman, U. and Kathju, S. (2004). Effect of water stress on moth bean [Vigna aconitifolia (JACQ) Marechal] genotypes. Indian J. Plant Physiol. 9(1): 29-35.

Goyal, V., Jai, S., Bishonoi, N.R. and Munjal, R. (2001). Leaf water relations, diffusive resistance and proline accumulation in hybrid pearl millet under depleting soil moisture content. Indian J. Plant Physiol. 6: 41-45.

Grassi, G. and Magnani, F. (2005). Stomatal, mesophyll conductance and biochemical limitations to photosynthesis as affected by drought and leaf ontogeny in ash and oak trees. Plant Cell Environ. 28: 834-849.

Hajheidari, M., Eivazi, A., Buchanan, B.B., Wong, J.H., Majidi, I. and Salekdeh, G.H. (2007). Proteomics uncovers a role for redox in drought tolerance in wheat. J. Proteome Res. 6: 1451-1460. 
Hsiao, T.C. 1973. Plant responses to water stress. Annual Rev. Plant Physio. 24: 519-570.

Jones, M.M., Turner, N.C. and Osmond, C.B. (1981). Mechanisms of drought resistance. In: The Physiology and Biochemistry of Drought Resistance in Plants. Paleg, L.G. and Aspinal, D. (eds.). Academic Press, Sydney, pp. 1535.

Kamara, A.Y., Menkir, A., Badu-Apraku, B. and Ibikunle, O. (2004). The influence of drought stress on growth, yield and yield components of selected maize genotypes. J. Agril. Sci. 141(01): 43-50.

Kang, J.Y., Choi, H.I., Im, M.Y. and Kim, S.Y. (2002). Arabidopsis basic leucine zipper proteins that mediate stressresponsive abscisic acid signaling. Plant Cell 14: 343-357.

Karaba, A., Dixit, S., Greco, R., Aharoni, A., Trijatmiko, K.R., Marsh-Martinez, N., Krishnan, A., Nataraja, K.N., Udayakumar, M. and Pereira, A. (2007). Improvement of water use efficiency in rice by expression of HARDY, an Arabidopsis drought and salt tolerance gene. Proc. Natl. Acad. Sci. USA 104: 15270-15275.

Kasuga, M., Miura, S., Shinozaki, K. and Yamaguchi-Shinozaki, K. (2004). A combination of Arabidopsis DREB1A gene and stress-inducible rd29A promoter improved drought- and lowtemperature stressed tolerance in tobacco by gene transfer. Plant Cell Physiol. 45: 346-350.

Kavar, T., Maras, M., Kidric, M., SustarVozlic, J. and Meglic, V. (2007). Identification of genes involved in the response of leaves of Phaseolus vulgaris to drought stress. Mol. Breed. 21: 159-172.

Keshavarzi, M., Miri, H.R. and Haghighi, B.J. (2013). Effect of water deficit stress on grain yield and yield components of wheat cultivars. Intern. J. Agron. Plant Prod. 4(6): 1376-1380.

Khodadadi, M. (2013). Effect of drought stress on yield and water relative content in chickpea. Intern. J. Agron. Plant Product. 4(6): 1168-1172.

Kobraei, S., Etminan, A., Mohammadi, R. and Kobraee, S. (2011). Effects of drought stress on yield and yield components of soybean. Ann. Biol. Res. 2(5): 504-509.

Kotabova, E., Kana, R.H., Kyselakova, K., Lipova, L., Novak, O. and Ilik, P. (2008). A pronounced light-induced zeaxanthin formation accompanied by an unusually slight increase in nonphotochemical quenching: A study with barley leaves treated with methyl viologen at moderate light. J. Plant Physiol. 165: 1563-1571.

Kramer, P.J. 1969. Plant and soil water relationship. TATA McGraw-Hill, Bombey New Delhi, pp. 360.

Kusaka, M., Ohta, M. and Fujimura, T. 2005. Contribution of inorganic components to osmotic adjustment and leaf folding for drought tolerance in pearl millet. Physiol. Plant., 125: 474-489.

Laporte, M.M., Shen, B. and Tarzynski, M.C. (2002). Senescing for drought avoidance: expression of maize NADPmalic enzyme in tobacco results in altered stomatal function. J. Expt. Bot. 53: 699-670.

Lawlor, D.W. and Cornic, G. (2002). Photosynthetic carbon assimilation and associated metabolism in relation to water deficits in higher plants. Plant Cell Environ. 25: 275-294.

Lee, Y.P., Kim, S.H., Bang, J.W., Lee, H.S., Kwak, S.S. and Kwon, S.Y. (2007). Enhanced tolerance to oxidative stress in transgenic plants expressing three antioxidant enzymes in chloroplasts. Plant Cell Rep. 26: 591-598. 
Levitt, J. (1972). Responses of plants to environmental stresses. Academic Press, New York.

Li, A.G., Hou, Y.S., Wall, G.W., Trent, A., Kimball, B.A. and Pinter, P.J. (2000). Free-air $\mathrm{CO}_{2}$ enrichment and drought stress effects on grain filling rate and duration in spring wheat. Crop Sci. 40: 1263-1270.

Li, L., Van Staden, J. and Jager, A.K. (1998). Effects of plant growth regulators on the antioxidant system in seedlings of two maize cultivars subjected to water stress. Plant Growth Regul. 25: 81-87.

Liu, Q., Kasuga, M., Sakuma, Y., Abe, H., Miura, S., Yamaguchi-Shinozaki, K. and Shinozaki, K. (1998). Two transcription factors, DREB1 and DREB2, with an EREBP/AP2 binding domain separate two cellular signals transduction pathways in drought- and low-temperature responsive genes in Arabidopsis. Plant Cell 10: 1391-1406.

Ludlow, M.M. and Muchow, R.C. (1990). A critical evaluation of traits for improving crop yields in water-limited environments. Adv. Agron. 43: 107-153.

Mansfield, T.A. and McAnish, M.R. (1995). Hormones and regulators of water balance. In: Plant Hormones Physiology, Biochemistry and Molecular Biology. Davies, P.J. (ed.). Academic Pub. pp. 589-616.

Masle, J., Gilmore, S.R. and Farquhar, G.D. (2005). The ERECTA gene regulates plant transpiration efficiency in Arabidopsis. Nature 436: 866-870.

Meyer, Y., Belin, C., Delorme-Hinoux, V., Reichheld, J.P. and Riondet, C. (2012). Thioredoxin and glutaredoxin systems in plants: molecular mechanisms, crosstalks, and functional significance. Antioxid Redox Signal. 17(8): 11241160.

Meyer, Y., Buchanan, B.B., Vignols, F. and Reicheld, J.P. (2009). Theoredoxins and glutaredoxins: unifying elements in redox biology. Ann. Rev. Genet. 43: 335-367.

Miao, Y., Lv, D., Wang, P., Wang, X.C., Chen, J., Miao, C. and Song, C.P. (2006). An Arabidosis glutathione peroxidase functions as both a redox transducer and scavenger in abscisic acid and drought stress response. Plant Cell 18: 2749-2766.

Mittler, R. (2002). Antoixodants and stress tolerance. Trends Plant Sci. 7: 405-410.

Moran, J.F., Becana, M., Iturbe-Ormaetxe, I., Frechilla, S., Klucas, R.V. and Aparicio-Tejo, P. (1994). Drought induces oxidative stress in pea plants. Planta 194: 346-352.

Munne-Bosch, S. and Penuelas, J. (2003). Photo- and antioxidative protection, and a role for salicyclic acid during drought and recovery in field-grown Phillyrea angustifolia plants. Planta 217: 758766.

Munné-Bosch, S., Jubany-Marí, T. and Alegre, L. (2003). Enhanced photo- and antioxidative protection, and hydrogen peroxide accumulation in droughtstressed Cistus clusii and Cistus albidus plants. Tree Physiol. 23(1): 1-12.

Mustilli, A.N., Merlot, S., Vavasseur, A., Fenzi, F. and Giraudat, J. (2002). Arabidopsis OST1 protein kinase mediates the regulation of stomatal aperture by abscisic acid and acts upstream of reactive oxygen species production. Plant Cell 14: 3089-3099.

Nakashima, K., Ito, Y. and YamaguchiShinozaki, K. (2009). Transcriptional regulatory networks in response to abiotic stresses in arabidopsis and grasses. Plant Physiol. 149: 88-95.

Neill, S.J. and Burnett, E.C. (1999). Regulation of gene expression during water deficit stress. Plant Growth Regul. 29: 23-33. 
Panta, G.R., Rieger, M.W. and Rowland, L.J. (2001). Effect of cold and drought stress on blueberry dehydrin accumulation. $J$. Hortic. Sci. Biotech. 76: 549-556.

Pastori, M.M. and Trippi, V.S. (1992). Oxidative stress induces high rate of glutathione synthesis in a droughtresistant maize strain. Plant Cell Physiol. 33: 957-961.

Patil, S.J., Panchal, Y.C. and Janardan, K.V. (1984). Effect of short time moisture stress on the proline and relative water content in chief plant parts of maize genotypes. Indian J. Plant Physiol. 27(4): 322-327.

Pattanagul, W. and Madore, M.A. (1999). Water deficit effects on raffinose family oligosaccharide metabolism of coleus. Plant Physiol. 121: 987-993.

Pellegrineschi, A., Reynolds, M., Pachew, M., Breto, R.M., Almeraya, R., YamaguchiShinozaki, K. and Hoisington, D. (2004). Stress-induced expression in wheat of the Arabidopsis thaliana DREB1 gene delay water stress symptoms under greenhouse conditions. Genome 47: 493-500.

Pelleschi, S., Rocher, J.P. and Prioul, J.L. (1997). Effect of water restriction on carbohydrate metabolism and photosynthesis in mature maize leaves. Plant Cell Environ. 20: 493-503.

Price, A.H., Cairas, J.E., Horton, P., Jones, H. and Griffiths, H. (2002). Linking drought resistance mechanisms to avoidance in upland rice using QTL approach: progress and new opportunities to integrate stomatal and mesophyll resistance responses. J. Exp. Bot. 53: 989-1004.

Ramakrishnayya, G. and Murty, K.S. (1991). Effect of soil moisture stress on tillering and grain yield in rice (Oryza sativa L.). Indian J. Agril. Sci. 61(3): 198-200.

Reyes, J.L., Compos, F., Wei, H., Arora, R., Yang, Y., Karlson, D.T. and
Cavarrubias, A.A. (2008). Functional dissection of hydrophillins during in vitro freeze protection. Plant Cell Environ. 31: 1781-1790.

Richards, R.A., Rawson, H.M. and Johnson, D.A. (1986). Glaucousness in wheat: its development, and effect on water-use efficiency, gas exchange and photosynthetic tissue temperatures. Australian J. Plant Physiol. 13: 465473.

Rivero, R.M., Kojima, M., Gepstein, A., Sakakibara, H., Mittler, R., Gepstein, S. and Blumwald, E. (2007). Delayed leaf senescence induces extreme drought tolerance in a flowering plant. Proc. Natl. Acad. Sci. USA 104: 1963119636.

Sairam, R.K., Deshmukh, P.S. and Saxena, D.C. (1998). Role of antioxidant systems in wheat genotypes tolerance to water stress. Biol. Plantarum 41: 387394.

Sato, Y. and Yokoya, S. (2008). Enhanced tolerance to drought stress in transgenic rice plants overexpressing a small heatshock protein, sHsp17.7. Plant Cell Rep. 27: 329-334.

Sayed, O.H. (1996) Adaptational responses of Zygophyllum qatarene Hadidi to stress conditions in a desert environment. $J$. Arid. Environ. 32: 445-452.

Schonfold, M.A., Johnson, R.C., Carver, B.F. and Mornhingweg, D.W. (1988). Water relations in winter wheat as drought resistant indicators. Crop Sci. 28: 526531.

Seki, M., Narusaka, M., Abe, H., Kasuga, M., Yamaguchi-Shinozaki, K., Carninci, P., Hiyashizaki, Y. and Shinozaki, K. (2001). Monitoring the expression pattern of 1300 Arabidopsis genes under drought and cold stresses by using a full-length cDNA microarray. Plant Cell 13: 61-72. 
Seki, M., Umezewa, T., Urano, K. and Shinizaki, K. (2007) Regulatory metabolic networks in drought stress response. Curr. Opin. Plant Biol. 10: 296-302.

Shao, H.B., Chu, L.Y. Shao, M.A., Abdul, Jaleel C. and Hong-Mei, M. 2008. Higher plant antioxidants and redox signaling under environmental stresses. Comp. Rend. Biol., 331: 433-441.

Sharma, K.D., Pannu, R.K., Tyagi, P.K., Chaudhary, B.D. and Singh, D.P. (2003). Effect of moisture stress on plant water relations and yield of different wheat genotypes. Indian $J$. Plant ZPhysiol. 8(1): 99-102.

Singh, K.B. 1993. Problems and prospects of stress resistance breeding in chickpea. In: Breeding for Stress Tolerance in Cool-Season Food Legumes, (eds. Singh, K.B., Saxena M.C.), John Wiley, U.K. pp. 17-35.

Slayter, R.O. 1973. The effect of internal water status on plant growth, development and yield. In: Plant Response to Climatic Factors. Slayter, R.O. (eds.). Proc. Uppsala Symp. UNESCO, Paris. pp. 177-191.

Sobarado, M.A. 1987. Leaf rolling: A visual indication of water deficit in corn (Zea mays L.). Maydica., 32: 9-18.

Stockginger, E.J., Gilmour, S.J. and Thomashow, M.F. (1997). Arabidopsis thaliana CBF1 encodes an AP2 domain-containing transcriptional activator that binds to C-repeats/DRE, a cis-acting DNA regulatory element that stimulates transcription in response to low temperature and water deficit. Proc. Natl. Acad. Sci. USA 94: 1035-1040.

Stuhlfauth, T., Steuer, B. and Fock, H.P. (1990). Chlorophyll and carotenoids under water stress and their relation to primary metabolism. Photosynth. 24: 412-418.
Sun, X., Fontaine, J.M., Rest, J.S., Shelden, E.A., Welsh, M.J. and Benndorf, R. (2004). Interaction of human HSP22 (HSPB8) with other small heat shock proteins. J. Biol. Chem. 279: 23942402.

Taiz, L. and Zeiger, E. (1998). Plant Physiology. Sinauer Associates, Inc. Publishers. Sunderland, Massachusetts.

Tang, L., Kwon, S.Y., Kim, S.H., Kim, J.S., Choi, J.S., Cho, K.Y., Sung, C.K., Kwak, S.S. and Lee, H.S. (2006). Enhanced tolerance of transgenic potato plants expressing both superoxide dismutase and ascorbate peroxidase in chloroplasts against oxidative stress and high temperature. Plant Cell Rep. 25: 1380-1386.

Tezara, W., Mitchel, V., Driscul, S.P. and Lawlor, D.W. 2002. Effects of water deficit and its interaction with $\mathrm{CO} 2$ supply on the biochemistry and physiology of photosynthesis in sunflower. Exp. Bot., 53: 1781-1791.

Tezara, W., Mitchel, V.J., Driscoll, S.D. and Lawlor, D.W. (1999). Water stress inhibits plant photosynthesis by decreasing coupling factor and ATP. Nature 401: 914-917.

Thomson, J.E., Legge, R.L. and Barber, R.F. (1987). The role of free radicals in senescence and wounding. New Phytol. 105: 317-344.

Torres-Franklin, M.L., Contour-Ansel, D., Zuily-Fodil, Y. and Pham-Thi, A.T. (2006) Molecular cloning of glutathione reductase cDNAs and analysis of GR gene expression in cowpea and common bean leaves during recovery from moderate drought stress. J. Plant Physiol. 165: 514-521.

Turkan, I., Bor, M., Ozdemir, F. and Koca, H. (2005). Differential responses of lipid peroxidation and antioxidants in the leaves of drought tolerant $P$. acutifolius Gray and drought-sensitive $P$. vulgaris 
L. subjected to polyethelene glycol mediated water stress. Plant Sci. 168: 223-231.

Turner, N.C. (1979). Drought resistance and adaptation to water deficit in crop plants. In: Stress Physiology in Crop Plants. Mussell, H. and Staples, R. (eds.). John Wiley and Sons, New York, pp. 343-372.

Turner, N.C., Wright, G.C. and Siddique, K.H.M. (2001). Adaptation of grain legumes (pulses) to water-limited environments. Adv. Agron. 71: 123-231.

Umezewa, T., Fujita, M., Fujita, Y., Yamaguchi-Shinozaky, K. and Shinozaki, K. (2006). Engineering drought tolerance in plants: discovering and tailoring genes unlock the truth. Curr. Opin. Plant Biotech. 17: 113-122.

Vasquez-Robinet, C., Mane, S.P., Ulanov, A.V., Watkinson, J.I., Stromber, V.K., De Koeyer, D., Schafleitner, R., Willmot, D.B., Bonierbale, M., Bohnert, H.J. and Grene, R. (2008). Physiological and molecular adaptation to drought in andean potato genotypes. J. Expt. Bot. 59: 2109-2123.

Venuprasad, R., Lafitte, H.R. and Atlin, G.N. (2007). Response to direct selection for grain yield under drought stress in rice. Crop Sci. 47: 285-293.

Verslues, P.E., Agarwal, M., KatiyarAgarwal, S., Zhu, J. and Zhu, J.K. (2006). Methods and concepts in quantifying resistance to drought, salt and freezing, abiotic stresses that affect plant water status. Plant J. 45: 523-539.

Vicre, M; Farrant, J.M. and Driovich, A. (2004). Insights into the cellular mechanisms of dessication tolerance among angiosperm resurrection plant. Plant Cell Rep. 27: 1329-1340.

Viner, R. I. and Clegg, J. S. (2001). Influence of trehalose on the molecular activity of p26, a small heat shock/crystallin protein. Cell Stress Chaperon 6: 126135.

Vu, T. C. V., Allen, L.H. and Bowes, G. (1987). Drought stress and elevated $\mathrm{CO}_{2}$ effects on soybean ribulose biphosphate carboxylase activity and canopy photosynthetic rates. Plant Physiol. 83: 573-578.

Wang, Y., Jiang, J., Zhao, X., Liu, G., Yang, C. and Zhan, L. (2006). A novel LEA gene from Tamarix androssowii confers drought tolerance in transgenic tobacco. Plant Sci. 171: 655-662.

Willumsen, J. 1993. Assessment of fluctuations in water and air content of pot substrates during plant growth. Acta. Hort., 295: 249-259.

Xiao, X., Huang, Y., Tang, N. and Xiong, L. (2007). Overexpression of a LEA gene in rice improves drought resistance under field conditions. Theor. Appl. Genet. 115: 35-46.

Xiong, L., Wang, R. G., Mao, G. and Koczan, J. (2006). Identification of drought tolerance determinants by genetic analysis of root responses to drought stress and abscisic acid. Plant Physiol. 142: 1065-1074.

Xu, D., Duan, X., Wang, B., Hong, B., Ho, T. and $\mathrm{Wu}, \mathrm{R}$. (1996). Expression of a late embryogenesis abundant protein gene, HVA1, from barley confers tolerance to water deficit and salt stress in transgenic rice. Plant Physiol. 110(1): 249-257.

Yadav, S. K., Lakshmi, N. J., Maheswari, M., Vanaja, M. and Venkateswarlu, B. (2005). Influence of water deficit at vegetative, anthesis and grain filling stages on water relation and grain yield in sorghum. Indian J. Plant Physiol. 10(1): 20-24.

Yadav, S.K., Lakshmi, N.J., Maheswari, M., Vanaja, M. and Venkateswarlu, B. (2005). Influence of water deficit at vegetative, anthesis and grain filling stages on water relation and grain yield 
in sorghum. Indian J. Plant Physiol. 10(1): 20-24.

Yamaguchi-Shinozaki, K. and Shinozaki, K. (2006). Transcriptional regulatory networks in cellular responses and tolerance to dehydration and cold stress. Ann. Rev. Plant Biol. 57: 781-803.

Yoshida, S. (1981). Fundamentals of rice crop science. The International Rice Research Institute, Los Banos, Philippines.
Zhang, J. and Kirkham, M.B. (1996). Enzymatic responses of the ascorbateglutathione cycle to drought in sorghum and sunflower. Plant Sci. 113: 139-147.

Zlatev, Z.S. and Yordanov, I.T. (2004). Effects of soil droughts on photosynthesis and chlorophyll florescence in bean plants. Bulg. $J$. Plant Physiol. 30(3-4): 3-18.

\section{How to cite this article:}

Diganta Deka, Anil Kumar Singh and Alok Kumar Singh. 2018. Effect of Drought Stress on Crop Plants with Special Reference to Drought Avoidance and Tolerance Mechanisms: A Review. Int.J.Curr.Microbiol.App.Sci. 7(09): 2703-2721. doi: https://doi.org/10.20546/ijcmas.2018.709.336 